\title{
Dietary Effects of Natural Polyphenol Antioxidant on Laying Performance and Egg Quality of Laying Hens Fed Diets with Oxidized Oil
}

\section{-Author(s)}

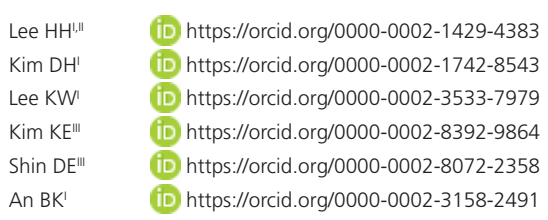

Department of Animal Science and Technology, Konkuk University, 120 Neungdong-ro, Gwangjingu, Seoul 05029, Republic of Korea.

Daeho Co., Ltd., Seoul 06563, Republic of Korea. R\&D Center, Nonghyup Feed, Seoul 05398, Republic of Korea.

\section{ABSTRACT}

This study was conducted to investigate the effects of dietary oxidized oil and natural polyphenol antioxidants on laying performances and egg quality of laying hens. A total of two hundred, 61-week-old Lohmann Brown laying hens were divided into five groups, consisting in four replicates of 10 birds each. They were fed one of the five experimental diets (fresh oil only, oxidized oil without antioxidants, oxidized oil with vitamin E 200 ppm, oxidized oil with vitamin E 100 ppm + Cabanin CSD ${ }^{\circledR} 100$ ppm, oxidized oil with Cabanin CSD ${ }^{\circledR} 500$ ppm)respectively, for 6 weeks. There were no significant differences in laying performances and egg weight among the treatments. However, egg mass in group fed oxidized oil with vitamin E 100 ppm + Cabanin CSD $^{\circledR} 100$ ppmwas significantly higher than group fed oxidized oil only $(p<0.05)$. Eggshell thickness and eggshell strength was not affected by feeding of oxidized oil and antioxidants. Haugh unit checked after storage of $14 \mathrm{~d}$ from the end date of the trial showed significant difference $(p<0.05)$. Serum superoxide dismutase (SOD) like activity was significantly higher in antioxidant treated groups. The level of serum glutamic oxaloacetic transaminase (GOT) was significantly lower in groups fed vitamin E 100 ppm + Cabanin CSD ${ }^{\circledR}$ 100 ppm or Cabanin CSD ${ }^{\circledR} 500$ ppm compared to groups fed oxidized oil without antioxidant. The number of total microbes, lactobacilli, and Enterocossus faecium showed significant difference favored to antioxidants groups. This study indicates that addition of oxidized oil to layer diet may have harmful effect on oxidative status and egg quality, but concurrent addition of vitamin $\mathrm{E}$ and natural polyphenol can alleviate the toxic effect of oxidized oil.

\section{INTRODUCTION}

Fat and oils are concentrated and relatively higher energy sources. These are routinely added to poultry diets to increase the energy density and to supply essential fatty acids. It is generally known that oils rich in polyunsaturated fatty acids (PUFA) have the advantage of digestion and absorption but are more prone to oxidation because of their double bonds, in particular, under the condition that heat is added (Urso \& Clarkson, 2003). Heat is inevitably applied in processing for feed manufacture and in frying for meal preparation from oilseeds. During repeated heat application, oxidative and thermal effects result in the formation of potentially toxic compounds (Warnants et al., 1996). Still controversial, direct products of fat oxidation including aldehydes, ketones and esters decreased available energy values of animal feeds (Shermer \& Calabotta, 1985). Zhang et al. (2011) suggested that oxidation of fats induces an unfavorable odor, causing quality problems such as lowering the nutritional value of chicken meat. 
The active antioxidants, vitamin $\mathrm{E}$ and selenium, have been shown to have a protective effect against oxidative changes (Meluzzi et al., 2000). Supplementation of these antioxidants reduced the formation of malondialdehyde (MDA) in eggs enriched with n-3 PUFA (Ren et al., 2013). The natural polyphenols also exhibited potent antioxidative and free-radical scavenging properties. Kang et al. (2010) suggested that blood total antioxidant status and intestinal superoxide dismutase (SOD) could be increased in laying hens fed natural antioxidant products. In previous studies, we found that Skullcap extract could be used as a valuable natural source for reducing lipid oxidation developed during storage (An et al., 2010). If so, it is anticipated that natural polyphenols will reduce oxidative change under the harsh conditions that cause oxidation, such as the feeding oxidized oil. The objective of this study was to test the effects that vitamin $\mathrm{E}$ and natural polyphenol antioxidants have on laying performances, egg quality and oxidative status of laying hens fed diets containing oxidized oil.

\section{MATERIALS AND METHODS}

\section{Test substrates}

Cabanin $\mathrm{CSD}^{\circledR}$ were composed of grape pomace extract, sweet chestnut extract, black current extract and citrus extract and provided by DaehoCo. Ltd. To obtain oxidized oil, fresh food grade soybean oils were purchased from the supermarket. The oils were contacted with oxygen for $96 \mathrm{~h}$ using a bubble generator and then heated at a temperature of $130^{\circ} \mathrm{C}$ for $8 \mathrm{~h}$ and stored for the rest of the time at room temperature. This work lasted 4 days. As finally identified, the acid value of oxidized oil and the peroxide value (POV) were $2.15 \mathrm{mg}$ of $\mathrm{KOH} / \mathrm{g}$ and $98.5 \mathrm{meg} / \mathrm{kg}$, respectively, and these values are similar to the heated soybean oil used in another study (Yue et al., 2011). The oil purchased at the same time was refrigerated to avoid further oxidative changes. Fatty acid composition of fresh and oxidized soybean oils is presented in Table 1.

\section{Animals, diets and management}

The Institutional Animal Care and Use Committee at Konkuk University approved the techniques and procedures involved in the animal care and handling (KU15186). An experiment was conducted using two hundred, 61-week-old Lohmann Brown laying hens and lasted 6 wks. The hens were housed in a caged layer house of commercial design with water and feed provided ad libitum. They were randomly assigned
Table 1 - Fatty acid compositions of fresh and oxidized soybean oils 1.

\begin{tabular}{|c|c|c|}
\hline Fatty acids & Fresh soybean oil & Oxidized soybean oil \\
\hline C14:0 & 0.00 & 0.28 \\
\hline$C 14: 1 \omega 5$ & 0.00 & 0.00 \\
\hline C 16:0 & 10.60 & 13.78 \\
\hline$C 16: 1 \omega 7$ & 0.00 & 1.19 \\
\hline C18:0 & 4.26 & 5.32 \\
\hline $\mathrm{C} 18: 1 \omega 9$ & 26.46 & 24.35 \\
\hline 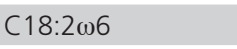 & 52.12 & 49.57 \\
\hline $\mathrm{C} 18: 3 \omega 3$ & 5.99 & 4.22 \\
\hline C20:0 & 0.00 & 0.44 \\
\hline$C 20: 1 \omega 9$ & 0.00 & 0.50 \\
\hline$C 20: 2 \omega 6$ & 0.00 & 0.00 \\
\hline$C 20: 3 \omega 6$ & 0.00 & 0.00 \\
\hline$C 20: 4 \omega 6$ & 0.00 & 0.00 \\
\hline$C 20: 5 \omega 3$ & 0.00 & 0.00 \\
\hline $\mathrm{C} 22: 0$ & 0.57 & 0.00 \\
\hline$C 22: 1 \omega 9$ & 0.00 & 0.00 \\
\hline$C 22: 6 \omega 3$ & 0.00 & 0.00 \\
\hline$C 24: 0$ & 0.00 & 0.35 \\
\hline SFA & 15.43 & 20.57 \\
\hline PUFA & 58.11 & 53.79 \\
\hline MUFA & 26.46 & 25.64 \\
\hline Total $\omega 3$ & 5.99 & 4.22 \\
\hline Total $\omega 6$ & 52.12 & 49.57 \\
\hline$\omega 6 / \omega 3$ & 8.70 & 11.75 \\
\hline SFA : MUFA : PUFA & $1: 1.71: 3.76$ & $1: 1.25: 2.61$ \\
\hline
\end{tabular}

1 SFA, saturated fatty acid; MUFA, monounsaturated fatty acid; PUFA, polyunsaturated fatty acid.

into the 5 experimental groups with 4 replicates of 10 hens each and reared under routine conditions of temperature $\left(25 \pm 3^{\circ} \mathrm{C}\right)$, humidity $(50 \%)$ and artificial lighting (15L/9D). Two hens at a time were put into one wire cage $(35 \times 40 \mathrm{~cm})$. The hens were fed one of the five experimental diets which were $P C$, fresh soybean oil only; NC, oxidized soybean oil only; T1, oxidized oil with vitamin E 200 ppm; T2, oxidized oil with vitamin E 100 ppm + Cabanin CSD $^{\circledR}$ (as natural polyphenol antioxidant) 100 ppm; T3, oxidized oil with Cabanin $\mathrm{CSD}^{\circledR} 500$ ppm, respectively. The composition of the experimental diet was based on the requirements stipulated by NRC (1994) for Brown laying hens and the nutrition levels were shown in Table 2. Diets were freshly added every day. Feed intake of each replicate was recorded weekly.

\section{Egg production}

Egg production and egg weight were measured daily. Daily average of egg weight was determined, excluding abnormal eggs and recorded on replicate basis. Egg mass was calculated as the percentage of egg production multiplied by the egg weight. Feed consumption were measured at the beginning and the 
Table 2 - Ingredients and composition of the basal diet (\%, as-fed basis) 1,2.

\begin{tabular}{|c|c|}
\hline Ingredients & \\
\hline Yellow corn & 46.49 \\
\hline Soybean meal & 11.23 \\
\hline Soybean oil (fresh or oxidized form) & 1.50 \\
\hline Corn dried distill'sgrains with dolubles & 6.00 \\
\hline Rapeseed meal & 3.00 \\
\hline Wheat bran & 6.70 \\
\hline Lupin & 7.00 \\
\hline Corn gluten meal & 2.20 \\
\hline Tallow & 0.60 \\
\hline Rice bran & 2.90 \\
\hline Limestone, coarse & 10.80 \\
\hline Mono dicalcium phosphate & 0.60 \\
\hline Salt & 0.20 \\
\hline L-Lys, 78\% & 0.22 \\
\hline DL-Met, 98\% & 0.08 \\
\hline Choline-Cl, 50\% & 0.08 \\
\hline Mineral premix & 0.17 \\
\hline Vitamin premix & 0.18 \\
\hline Sodium bicarbonate & 0.05 \\
\hline Total & 100.00 \\
\hline \multicolumn{2}{|l|}{ Calculated Analysis of basal diet } \\
\hline$C P, \%$ & 16.50 \\
\hline Crude fat, \% & 4.12 \\
\hline Crude fiber, \% & 3.59 \\
\hline Crude ash, \% & 13.95 \\
\hline Avail. P, \% & 0.45 \\
\hline $\mathrm{Ca}, \%$ & 4.18 \\
\hline TMEn, kcal/kg & 2,750 \\
\hline
\end{tabular}

${ }^{1}$ Mineral mixture provided following nutrients per kg of diet: $\mathrm{Fe}, 55 \mathrm{mg} ; \mathrm{Zn}, 88 \mathrm{mg} ; \mathrm{Mn}$, 88mg; Cu, 5.5mg; I, 1.7mg; Se, 0.3mg;

${ }^{2}$ Vitamin mixture provided following nutrients per $\mathrm{kg}$ of diet: vitamin $\mathrm{A}, 8,666 \mathrm{IU}$; vitamin $\mathrm{D}_{3^{\prime}}$ 2,666 IU; vitamin $\mathrm{E}$, $20 \mathrm{IU}$; vitamin $\mathrm{K}_{3^{\prime}}$, $2 \mathrm{mg}$; vitamin $\mathrm{B}_{1}$, 2mg; vitamin $\mathrm{B}_{2^{\prime}}$ 4.6mg; vitamin $B_{6}, 3.3 \mathrm{mg}$; vitamin $B_{12}, 0.013 \mathrm{mg}$; biotin, $0.1 \mathrm{mg}$; niacin, $33 \mathrm{mg}$; pantothenic acid, 8mg; folic acid, $1 \mathrm{mg}$

end of the experimental period, and average daily feed intake, and egg production were adjusted for mortality.

\section{Egg quality measurements}

Egg qualities were determined at a $7 \mathrm{~d}$ interval. Five eggs from each replicate were collected, individually weighed and stored overnight at room temperature for subsequent measurements. The breaking strength of uncracked eggs was measured with an eggshell strength tester (FHK, Fujihara Ltd., Tokyo, Japan). Eggshell thickness without shell membrane was measured with a micrometer (Digimatic micrometer, Series 293-330, Mitutoyo, Japan). Albumen height was measured using Egg multi-tester (QCM+ Technical Services and Supplies Ltd., York, England). Haugh unit, along with albumen height and egg weight, was calculated as previously described (An et al., 2010). Egg yolk color was measured by comparing to Roche yolk color fan (Hoffman-La Roche Ltd., Basel, Switzerland). The collected eggs were kept in storage temperature of $18^{\circ} \mathrm{C}$ during 7 or $14 \mathrm{~d}$ to observe the change of Haugh unit.

\section{Blood sampling and analysis}

At the end of the experimental period, blood samples were collected from the jugular vein of 8 birds per each treatment. After centrifugation at 2,000 $\times g$ for $15 \mathrm{~min}$ the serum samples were stored at $-60^{\circ} \mathrm{C}$ until analysis. The activities of glutamic oxaloacetic transaminase (GOT) and glutamic pyruvic transaminase (GPT) in sera sampled were measured with colorimetric method using GOT-GPT assay kits (Asan Pharmaceutical Co., Korea) according to the manufacture's direction. For superoxide dismutase (SOD) like activity test, $2 \mathrm{ml}$ of Tris- $\mathrm{HCl}$ buffer $(\mathrm{pH} 8.5)$ and $0.1 \mathrm{ml}$ of $5 \mathrm{mM}$ pyrogallol were incubated with or without sera at $25^{\circ} \mathrm{C}$ for 30 min. The reaction was stopped with $0.1 \mathrm{ml}$ of $1 \mathrm{~N} \mathrm{HCl}$, which was followed by reading the absorbance at 405 $\mathrm{nm}$ against the blank (Marklind \& Marklund, 1974).

\section{Measurement of malondialdehyde}

Some modified methods were used to determine thiobarbituric acid reactive substances (TBARs) values in egg yolk to evaluate lipid oxidation as described by Botsoglou et al. (1994). To study the oxidative stability of egg yolk, 8 eggs from each group was placed in a high temperature cabinet over 3 days of storage at $35^{\circ} \mathrm{C}$. A $1.5 \mathrm{~g}$ egg yolk sample was homogenized with $5 \%$ aqueous trichloroacetic acid solution containing $0.8 \%$ butylated hydroxytoluene and then centrifuged for $3 \mathrm{~min}$ at $3,000 \mathrm{~g}$. Following reaction with thiobarbituric acid reagent, MDA was directly quantified by thirdderivative spectrophotometry against blank reaction mixture (Beckman DU-650, Beckman Counter, Inc.).

\section{Cecal microbial population}

Cecal contents of slaughtered birds were aseptically sampled and immediately chilled on ice for microbial test at the end of the experimental period. Immediately, digesta homogenates in PBS were serially diluted from $10^{-1}$ to $10^{-7}$ and subsequently plated onto duplicate selective agar media for enumeration of target bacterial strains. Total microbes, coliforms, lactic acid bacteria, and Enterocossus faecium were enumerated using plate count agar, MacConkey agar, and MRS agar, respectively. Each plate was incubated at $37^{\circ} \mathrm{C}$, for 24 to $72 \mathrm{~h}$ anaerobically or aerobically. The number of colonies were then counted. Results obtained were presented as base-10 logarithm colony-forming units per gram of cecaldigesta. 


\section{Statistical analysis}

The main effects between treated groups were subjected to ANOVA using the general linear models procedure of SAS (2002) and significant differences were determined using Duncan's multiple range test at the level of $p<0.05$. Differences between $0.05<p<0.10$ were discussed as a trend toward significance. Log transformation was performed for variables that was not normally distributed.

\section{RESULTS}

The levels of C 16:0 and C18:0 of oxidized soybean oil were slightly higher as compared with fresh soybean oil. Oxidized soybean oil contained less unsaturated fatty acid, such as C18:1 $\omega 9$, C18:2 $\omega 6$ and C18:3 $\omega 3$. The rate of SFA:MUFA:PUFA of oxidized oil was numerically decreased through repetitive heat treatment (Table 1).
Egg production and egg weight were not significantly affected by dietary treatments (Table 3). As compared with NC, hens fed oxidized oil with vitamin E 100 ppm + Cabanin CSD $^{\circledR} 100$ ppm showed a higher daily egg mass $(p<0.01)$. No significant difference was found among groups in feed intake $(p<0.05)$.

As shown in Table 4, Egg quality parameters did not show significant responses to the dietary treatments $(p<0.05)$. Dietary antioxidant supplementation did not affect the Haugh unit of eggs stored for $1 \mathrm{~d}$ or $7 \mathrm{~d}$. However, the Haugh unit of the group fed diet containing oxidized oil with Cabanin CSD ${ }^{\circledR} 50$ ppm was significantly higher $(p<0.05)$ than NC or PC over14 $\mathrm{d}$ of storage at $18^{\circ} \mathrm{C}$ (Table 5). The Haugh unit of eggs stored for $14 \mathrm{~d}$ was the lowest numerically in NC group. In contrast, MDA contents of egg yolk tended to decreased in groups fed antioxidants $(p<0.10)$. The serum SOD like activity in supplemental vitamin E 200

Table 3 - Dietary effects of dietary vitamin E and natural antioxidants on laying performances in laying hens fed oxidized oil 1,2 .

\begin{tabular}{|c|c|c|c|c|c|c|c|}
\hline & PC & $\mathrm{NC}$ & T1 & $\mathrm{T} 2$ & T3 & SEM & $p$-value \\
\hline Egg production rate, \% & 73.5 & 71.7 & 73.1 & 76.2 & 75.1 & 1.33 & 0.144 \\
\hline Egg weight, g/egg & 62.81 & 61.89 & 63.02 & 63.63 & 61.98 & 0.53 & 0.144 \\
\hline Egg mass & $46.2^{\mathrm{ab}}$ & $44.4^{\mathrm{b}}$ & $46.1^{\mathrm{ab}}$ & $48.5^{a}$ & $46.6^{\mathrm{ab}}$ & 0.69 & 0.004 \\
\hline Feed intake, g/day/bird & 110.37 & 107.26 & 110.50 & 112.30 & 108.60 & 4.24 & 0.925 \\
\hline
\end{tabular}

'PC, fresh soybean oil only; NC, oxidized soybean oil only, T1, NC + vitamin E 200 ppm; T2, NC + vitamin E 100 ppm + Cabanin CSD ${ }^{\circledR} 100$ ppm; T3, NC + Cabanin CSD ${ }^{\circledR} 500$ ppm; SEM, pooled standard error of the means.

${ }^{2}$ Data are mean of 4 replicates with 5 cages with 2 birds per cage.

a,bValues with different superscripts within a row differ significantly $(p<0.05)$.

Table 4 - Dietary effects of dietary vitamin E and natural antioxidants on egg qualities in laying hens fed oxidized oil 1, 2.

\begin{tabular}{|c|c|c|c|c|c|c|c|}
\hline & PC & NC & T1 & $\mathrm{T} 2$ & T3 & SEM & $p$-value \\
\hline Yolk color, R.C.F & 6.72 & 6.89 & 6.70 & 6.75 & 6.75 & 0.09 & 0.612 \\
\hline Eggshell thickness, mm/100 & 34.63 & 34.17 & 34.44 & 34.08 & 34.56 & 0.33 & 0.711 \\
\hline Eggshell strength, $\mathrm{kg} / \mathrm{cm}^{2}$ & 2.56 & 2.41 & 2.36 & 2.33 & 2.42 & 0.07 & 0.280 \\
\hline
\end{tabular}

${ }^{1}$ PC, fresh soybean oil only; NC, oxidized soybean oil only, T1, NC + vitamin E 200 ppm; T2, NC + vitamin E 100 ppm + Cabanin CSD ${ }^{\circledR} 100$ ppm; T3, NC + Cabanin CSD®500 ppm; SEM, pooled standard error of the means.

${ }^{2}$ Mean values from the overall experiment period.

Table 5 - Dietary effects of dietary vitamin E and natural antioxidants on the change of Haugh unit, yolk lipid peroxidation and blood profiles in laying hens fed oxidized oil $1,2$.

\begin{tabular}{lccccccc}
\hline & PC & NC & T1 & T2 & T3 & SEM & p-value \\
\hline Haugh unit & & & & & & & \\
\hline $1 \mathrm{~d}$ & 76.17 & 76.49 & 73.99 & 75.26 & 78.23 & 3.62 & 0.944 \\
$7 \mathrm{~d}$ & 62.82 & 63.24 & 66.68 & 66.85 & 67.83 & 2.86 \\
$14 \mathrm{~d}$ & $44.24^{\mathrm{b}}$ & $42.40^{\mathrm{b}}$ & $47.33^{\mathrm{ab}}$ & $49.55^{\mathrm{ab}}$ & $53.30^{\mathrm{a}}$ & 2.41 & 0.635 \\
MDA, $\mu$ g/g yolk & 0.039 & 0.058 & 0.041 & 0.032 & 0.035 & 0.007 & 0.097 \\
SOD, IU/L & $62.61^{\mathrm{a}}$ & $50.08^{\mathrm{b}}$ & $65.80^{\mathrm{a}}$ & $57.60^{\mathrm{ab}}$ & $65.31^{\mathrm{a}}$ & 3.69 & 0.024 \\
GOT, IU/L & $109.99^{\mathrm{ab}}$ & $125.53^{\mathrm{a}}$ & $116.31^{\mathrm{ab}}$ & $80.96^{\mathrm{b}}$ & $81.46^{\mathrm{b}}$ & 12.47 & 0.042 \\
GPT, IU/L & 31.42 & 29.03 & 24.62 & 37.75 & 29.90 & 2.84 & 0.056 \\
\hline
\end{tabular}

'PC, fresh soybean oil only; NC, oxidized soybean oil only, T1, NC + vitamin E 200 ppm; T2, NC + vitamin E 100 ppm + Cabanin CSD ${ }^{\circledR 100 ~ p p m ; ~ T 3, ~ N C ~+~ C a b a n i n ~ C S D ~}{ }^{R 500 ~ p p m ; ~}$ MDA, malondialdehyde; SOD, superoxide dismutase; GOT, glutamic-oxaloacetic transaminase; GPT, glutamic-pyruvic transaminase; SEM, pooled standard error of the means.

${ }^{2}$ Haugh unit is expressed as means of 20 eggs and other data are expressed as means of 8 replicate per dietary group.

$a, b$ Values with different superscripts within a row differ significantly $(p<0.05)$. 
ppm or Cabanin $\mathrm{CSD}^{\circledR} 500$ ppm diet fed hens were significantly higher $(p<0.05)$ as compared with NC. In contrast, levels of serum GOT in group with vitamin E 100 ppm + Cabanin CSD $^{\circledR} 100$ ppm or CSD $^{\circledR} 500$ ppm were significantly lower $(p<0.05)$ than that of NC. No significant differences in level of GPT were observed among all groups.

The effects of dietary oxidized oil and antioxidant on the profiles of cecal microflora are summarized in Table 6. Compared with PC, the total microbe significantly decreased $(p<0.05)$ with dietary natural antioxidant supplementation. The number of Lactobacilli was significantly increased $(p<0.05)$, with dietary natural antioxidant supplementation (group fed diet with vitamin E 100 ppm +Cabanin CSD ${ }^{\circledR} 100$ ppm or $\mathrm{CSD}^{\circledR} 500$ ppm). The number of coliform bacteria was not significantly affected by dietary treatments.

Table 6 - Dietary effects of dietary vitamin E and natural antioxidants on theprofiles of cecal microflora in laying hens fed oxidized oil 1,2 .

\begin{tabular}{|c|c|c|c|c|c|c|c|}
\hline & PC & NC & T1 & $\mathrm{T} 2$ & T3 & SEM & $p$-value \\
\hline Total microbes, logcfu/g & $5.47^{a}$ & $5.13^{\mathrm{ab}}$ & $5.37^{a}$ & $4.87^{b}$ & $4.75^{b}$ & 0.16 & 0.013 \\
\hline E. coli, logcfu/g & 4.57 & 5.16 & 4.12 & 4.12 & 4.01 & 0.21 & 0.380 \\
\hline Lactobacilli, logcfu/g & $5.31^{b}$ & $5.25^{b}$ & $5.27^{b}$ & $5.79^{\mathrm{a}}$ & $6.03^{\mathrm{a}}$ & 0.11 & $<0.001$ \\
\hline Eterococcusfaecium logcfu/g & $5.07^{\mathrm{bc}}$ & $4.60^{c}$ & $4.88^{\mathrm{bc}}$ & $5.67^{\mathrm{a}}$ & $5.15^{b}$ & 0.15 & $<0.001$ \\
\hline
\end{tabular}

${ }^{1} P C$, fresh soybean oil only; NC, oxidized soybean oil only, T1, NC + vitamin E 200 ppm; T2, NC + vitamin E 100 ppm + Cabanin CSD ${ }^{\circledR} 100$ ppm; T3, NC + Cabanin CSD ${ }^{\circledR 500 ~ p p m ; ~}$ SEM, pooled standard error of the means.

${ }^{2}$ Data are expressed as means of 8 replicate per dietary group.

$a, b, c$ Values with different superscripts within a row differ significantly $(p<0.05)$.

\section{DISCUSSION}

It has been well known that the oxidized oil exerted nutritionally harmful effect that would have been added to animal feeds (Shermer \& Calabotta, 1985). The harmful effects ranged from slight reduction of performance to fatal toxicity leading to death. Oxidative changes also affected the structure that constituted the oil. Oxidized soybean oil used in this study contained less monounsaturated and polyunsaturated fatty acids and more saturated fatty acids, this means that the nutritional quality was lowered by oxidation. Consistence result has been reported by Gulla \& Waghray (2011), who observed a gradual increase in C16:0 and C18:0 and decreased in C18:1 $\omega 9$ and C18:2 $\omega 6$ when sesame oil was stored for $12 \mathrm{mo}$.

The objective of this study was to investigate whether the dietary oxidized oil have an adversary impact on laying performance and addition of vitamin $\mathrm{E}$ or natural antioxidant could alleviate the negative effect of oxidized oils. Unexpectedly, the egg production and feed intake were not affected by either supplemental oxidized oil or antioxidants. Instead, hens fed oxidized oil with vitamin E 100 ppm +Cabanin CSD ${ }^{\circledR} 100$ ppm showed a higher daily egg mass $(p<0.01)$ as compared with groups fed oxidized oil only. Yue et al. (2011) found no perceivable effect on feed intake and egg production and Lewis-McCrea \& Lall (2007) did not also observe an effect on egg production by dietary oxidized oil. The inconsistence results have been reported by Cabel et al. (1988) and Sanchez-Muniz et al. (1998), who found a significant reduction in egg production and feed efficiency by dietary oxidized oil. Dietary natural antioxidant or vitamin $\mathrm{E}$ has been demonstrated to improve laying performance (Radwan Nadia et al., 2008). Ajakaiye et al. (2011) reported that dietary addition of 150 ppm vitamin E could improve the egg weight and oxidative stability in laying hens raised at high temperature. These results indicate that the use of antioxidants may prevent deterioration of productivity under the condition where oxidative damage is expected.

We found that the Haugh unit was not affected during $1 \mathrm{~d}$ or $7 \mathrm{~d}$ of storage at $18^{\circ} \mathrm{C}$, but decreased significantly over the following $14 \mathrm{~d}$ of storage in group fed oxidized oil only. The Haugh unit of layers fed oxidized oil with Cabanin CSD $^{\circledR 500}$ ppm was significantly higher than NC group. The Haugh unit, an indicator of the most widely accepted measure of internal egg quality, tended to decrease according to the elapsed time of storage (Williams, 1992). It suggested that certain antioxidants such as vitamin C, vitamin E and selenium being beneficial to albumen quality by it's antioxidant property. Lim et al. (2006) reported that Haugh unit was linearly increased with increasing dietary garlic powder during storage and this was presumed to be due to the antioxidant properties of garlic powder. An et al. (2010), however, demonstrated that the Haugh units in the groups fed diets containing Skullcap extract tended to increase after 2 weeks of storage, but not significantly. These different responses 
were partly attributed to differences in type of natural substances, storage conditions of eggs and oxidative status of laying hens. It is also suggested that dietary antioxidant nutrients and natural antioxidants are effective in improving the quality of eggs and meats during extended storage (Surai, 2000). When vitamin $E$ was fed, the TBRA in eggs enriched with PUFAs was reduced at $40 \mathrm{~d}$ of storage (Cherian et al., 1996). In previous study, we also observed that dietary use of Skullcap extract has been demonstrated to reduce lipid oxidation of egg yolks (An et al., 2010). In this study, the levels of MDA in stored eggs were numerically decreased, but not significantly, by dietary antioxidant supplementation and this is probably because the storage period was relatively short.

Overall, serum SOD like activity and GOT levels were significantly affected by dietary treatments. The results of serum SOD like activity clearly showed that there were differences between groups of fresh oil and oxidized oils. Dietary supplementation of vitamin E 200 ppm or Cabanin CSD ${ }^{\circledR} 500$ ppm increased significantly the serum SOD like activity as compared with NC. This result is supported by a report that blood total antioxidant status and intestinal SOD could be increased in laying hens fed natural products, which has a high content of antioxidants (Kang et al., 2010). The SOD is one of the most important antioxidant enzymes and plays a role in protecting cells from damage caused by reactive oxygen species (Marklind \& Marklund, 1974). The serum SOD like activity results shown in this study suggest that oxidized oil decreases the antioxidant capacity, while vitamin $\mathrm{E}$ and Cabanin $\mathrm{CSD}^{\circledR}$ may improve the antioxidant status of laying hens by elevating the activity of antioxidant enzyme. Serum GOT is closely related liver and tissue damages in avian and are valuable for the determination of safety of new feedstuffs and feed additives (Diaz et al. 2003). In our current study, the level of serum GOT was the highest in group fed oxidized oil without antioxidants and this in an indication that oxidized oil may have a negative effect on liver function. Serum GOT also increased in rats fed diet containing autoxidized safflower oil (Nakamura et al., 1973). In contrast, the levels of serum GOT were significantly lower in Cabanin CSD $^{\circledR}$ fed groups compared to groups fed oxidized oil without antioxidant.

The number of Lactobacilli significantly increased $(p<0.05)$, with dietary natural antioxidant supplementation. The observed beneficial effect of Cabanin $\operatorname{CSD}^{\circledR}$ agree with our previous report with cecal microbial population (An et al., 2010). Jamroz et al. (2005) also reported a decrease in E Coli and an increase in Lactobacillus pp. of chicks fed plant extracts. On the other hand, Cross et al. (2007) observed that the profiles of gut microflora were not affected by feeding herbs or their associated essential oil. In this study, the natural antioxidant, Cabanin $\operatorname{CSD}^{\circledR}$ added to diets modulated the profiles of cecal microflora, reflecting a potential to alter gut micro ecology in laying hens.

The present study gives evidence that not only vitamin $E$ but the natural antioxidant efficiently prevents lipid oxidation under the condition where oxidative damage is expected. There are demands for using natural products that can prevent lipid oxidation in lipid enriched animal foods, due to consumer preferences for natural substances and toxicological concerns of synthetic antioxidants (Miller et al., 2005). The natural antioxidant, Cabanin CSD $^{\circledR}$ can fully replace the antioxidant function of vitamin $E$ and be used as a valuable source for reducing oxidative stress and maintaining liver function.

\section{CONFLICTOF INTERESTS}

We declare that we have no financial or personal relationships with other organizations that can inappropriately influence our work.

\section{ACKNOWLEDGEMENTS}

This paper was supported by the KU Research Professor Program of Konkuk University (314028-033-CG000).

\section{REFERENCES}

Ajakaiye JJ, Perez-Bello A, Molloneda-Trujillo A. Impact of heat stress on egg quality in layer hens supplemented with I-ascorbic acid and dltocopherol acetate. Veterinarski Arhiv 2011;81:119-132.

An BK, Kwon HS, Lee BK, Kim JY, You SJ, Kim JM, et al. Effects of dietary skullcap (Scutellaria baicalensis) extract on laying performance and lipid oxidation of chicken eggs. Asian Australasian Journal of Animal Science 2010;23:772-776.

Botsoglou NA, Fletouris DJ, Papageorgiou GE, Vassilopoulos VN, Mantis AJ, Trakatellis AG. Rapid, sensitive, and specific thiobarbituric acid method for measuring lipid peroxidation in animal tissue, food and feedstuff samples. Journal of Agricultural and Food Chemistry 1994;42:19311937.

Cabel MC, Waldroup P, Shermer WD, Calabotta DF. Effects of ethoxyquin feed preservative and peroxide level on broiler performance. Poultry Science 1988;67:1725-1730

Cherian G, Wolfe FH, Sim JS. Feeding dietary oils with tocopherols: effects on internal qualities of eggs during storage. Journal of Food Science1996;61:15-18. 
Cross DE, Mcdevitt RM, Hillman K, Acamovic T. The effect of herbs and their associated essential oils on performance, dietary digestibility and gut microflora in chickens from 7 to 28 days of age. British Poultry Science 2007;48:496-506.

Diaz GJ, Roldan LP, Cortes A. Intoxication of Crotalaria pallida seeds to growing broiler chicks. Veterinary and Human Toxicology 2003;45:187189.

Gulla S, Waghray K. Effect of storage on physico-chemical characteristics and fatty acid composition of selected oil blends. Journal of Life Science 2011;3:35-46.

Jamroz D, Wiliczkiewicz A, Wertelecki T, Orda J, Skorupinska J. Use of active substances of plant origin in chicken diets based on maize and locally grown cereals. British Poultry Science 2005;46:485-493.

Kang SY, Lee MH, Ko YH, Sohn SH, Moon YS, Jang IS. Effect of dietary supplementation of Acanthopanax senticosus and Eucommia ulmoides on antioxidant defense system in laying hens. Korean Journal of Poultry Science 2010;37:15-21.

Lewis-McCrea LM, Lall SP. Effects of moderately oxidized dietary lipid and the role of vitamin $\mathrm{E}$ on the development of skeletal abnormalities in juvenile Atlantic halibut (Hippoglossus hippoglossus). Aquaculture 2007;262:142-155.

Lim KS, You SJ, An BK, Kang CW. Effects of dietary garlic powder and copper on cholesterol content and quality characteristics of chicken eggs. Asian Australasian Journal of Animal Science 2006;19:582-586.

Marklund S, Marklund G. Involvement of the superoxide anion radical in the autoxidation of pyrogallol and a convenient assay for superoxide dismutase. European Journal of Biochemistry 1974;47:469-474.

Meluzzi A, Sirri F, Manfreda, Tallarico N, Franchini A. Effects of dietary vitamin $E$ on the quality of table eggs enriched with $n-3$ long-chain fatty acids. Poultry Science 2000;79:539-545.

Miller ER, Pastor-Barriuso R, Dalal D, Riemersma RA, Aplle LJ, Guallar E. Meta-analysis: high-dosage vitamin $\mathrm{E}$ supplementation may increase all-cause mortality. Annals of Internal Medicine 2005;142:37-46.

Nakamura M, Tanaka H, Hottori Y, Watanabe M. Biological effects of autoxidized safflower oils. Lipids 1973;8:566-572.
NRC - National Research Council. Nutrient requirements of poultry. $9^{\text {th }}$ ed Washington: National Academy Press; 1994.

Radwan Nadia L, Hassan RA, Qota EM, Fayek HM. Effect of natura antioxidant on oxidative stability of eggs and productive and reproductive performance of laying hens. International Journal of Poultry Science 2008;7:134-150.

Ren Y, Perez TI, Zuidhof MJ, Renema RA, Wu J. Oxidative stability of omega-3 polyunsaturated fatty acids enriched eggs. Journal of Agricultural and Food Chemistry 2013;61:11595-11602.

Sanchez-Muniz FJ, Lopez-Varela S, Garrido-Polonio MC, Cuesta C. Dietary effects on growth, liver peroxides, and serum and lipoprotein lipids in rats fed a thermo oxidised and polymerised sunflower oil. Journal of the Science of Food and Agriculture 1998;76:364-372.

SAS. SAS user's guide. Statistics. Version 8. Cary: SAS Institute; 2002.

Shermer WD, Calabotta DF. Oxidation of feed: How much has occurred? Feedstuffs 1985;4:19-20.

Surai PF. Effect of selenium and vitamin E content of maternal diet on the antioxidant system of the yolk and the developing chicks. British Poultry Science 2000;41:235-243.

Urso ML, Clarkson PM. Oxidative stress, exercise and antioxidant supplementation. Toxicology 2003;189:41-54.

Warnants N, Vanoeckel MJ, Boucque CV. Incorporation of dietary polyunsaturated fatty acids in porks tissues and its implication for the quality of the end products. Meat Science 1996;44:125-144.

Williams KC. Some factor affecting albumen quality with particular reference to Haugh unit score. World's Poultry Science Journal 1992;48:5-16.

Yue HY, Wang J, Qi XL, Ji F, Liu MF, Wu SG, et al. Effects of dietary oxidized oil on laying performance, lipid metabolism, and apolipoprotein gene expression in laying hens. Poultry Science 2011;90:1728-1736.

Zhang W, Xiao S, Lee EJ, Ahn DU. Effect of dietary oxidation on the quality of broiler breast meat. Iowa: lowa State University Animal Industry Report; 2011. 
